MATEC Web of Conferences 22,02025 (2015)

DOI: $10.1051 /$ matec conf/ 20152202025

(C) Owned by the authors, published by EDP Sciences, 2015

\title{
A Novel Neutral Point Voltage Control Strategy for Three-Level NPC APF Based on SVPWM
}

\author{
Xiaolong Yao*, Yonggeng Lu, Ziyang Jin \& Bin Zhang \\ College of Electrical Engineering, Shanghai Dianji University, Shanghai, China
}

\begin{abstract}
The unbalance of the neutral point voltage is an inherent problem of three-level neutral-point-clamped (NPC) Active Power Filter (APF); this paper analyzes the causes of unbalanced neutral point voltage and studies the reason of the unbalance of the neutral point voltage. A novel neutral point voltage control strategy using Space Vector Pulse Width Modulation (SVPWM) is proposed. The proposed strategy is based on the traditional SVPWM, by controlling the effect time of small vector, which can change the state of the midpoint voltage fluctuation, and the neutral point voltage can be maintained balance. The influence of the vector on neutral point balance is investigated in depth. Simulation results show the neutral point voltage balancing control strategy based on SPWM is effective.
\end{abstract}

Keywords: three-level APF; neutral point voltage balance strategy; SVPWM

\section{INTRODUCTION}

Recently, there is growing demand for less harmonics and higher voltage level in medium-voltage and high-voltage applications, such as industrial drive, traction and power system. Compared to the two-level inverter, the voltage stress on switching devices is reduced, the output voltage and current are better with lower harmonics [1-4]. Therefore, the neutral point clamped three-level APF is now becoming increasingly popular. Figure 1 shows the NPC three-level APF topology and the connection relationship with the power system.

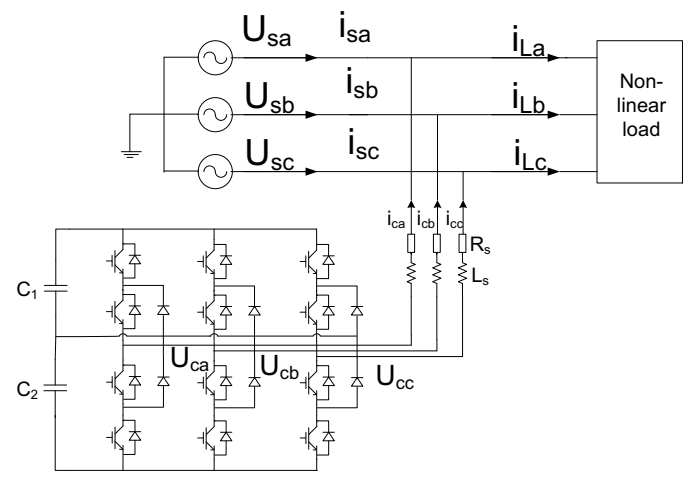

Figure 1. NPC three-level APF topology and the connection relationship with the power system

However, the NPC three-level APF has an inherent problem of the neutral point voltage balance. It will increase the output voltage harmonics; damage the switching devices and dc-link capacitors. There are many reasons of the unbalance, such as dissimilarity in dc-link capacitors provided from the manufacturer, the effects of different vectors, load unbalancing and non-uniform charge distribution and so on. When occurrence unbalancing in DC-link voltage, the neutral point potential (NPP) deviates from its reference value which is zero. As a result, the unbalance may bring much more serious detriments: the output voltage will be a serious distortion and then there will have some low frequency harmonics; the distorted voltage and current will influence electric equipment's system operating performance; the voltage scale and switching stress of power devices such as IGBT will increase the total cost of the system and huge wasting of resources; yet the service life of the DC-link capacitors also may be shorter than expectation [5].

The SVPWM scheme uses the nearest three vectors to synthesize the reference vector [6-7]. The method can overcome the neutral point voltage problems: changing the vector switching sequence and changing the effective times of the vectors. Redundant states of the small vectors can be selected to maintain the neutral point voltage balance. Each small vector has two redundant states: positive small vector and negative small vector. These two states generate the same output voltage vector; however, they have the opposite control effect on the neutral point voltage. Therefore, redundant small vectors are used for neutral point voltage control.

This paper presents a novel neutral point voltage balance control strategy based on regulating factor. The neutral point voltage is controlled by changing the variation time of the small voltage vectors. Simulation and experimental results show that the strategy has good capability for neutral point voltage balance.

*Corresponding author: dqxlyao@gmail.com

This is an Open Access article distributed under the terms of the Creative Commons Attribution License 4.0, which permits unrestricted use, distribution, and reproduction in any medium, provided the original work is properly cited. 


\section{SVPWM SCHEME FOR NPC THREE-LEVEL $\mathrm{APF}$}

In the three-phase three-level NPC APF, each phase has three output switching states named "P", "O" and "N", in which "P" means high level and the AC output phase voltage is $+1 / 2 \mathrm{Udc}$, "O" means zero level and $\mathrm{AC}$ the output phase voltage is 0 , and " $\mathrm{N}$ " means low level and the AC output phase voltage is $-1 / 2 \mathrm{Udc}$. The three states can be combined into a total of 27 possible switching states, and the total 27 switching states correspond to 19 space voltage vectors, and the space vector diagram is shown in Figure 2. The plane is divided into six triangular sectors (section I, II , III, IV, V and VI) by large vectors. And each sector can be divided into six regions $(1,2,3,4,5$ and 6$)$. For the nearest three vectors (NTV) SVPWM strategy, reference output voltage is compounded by the nearest three vectors according to the equivalence of the volt-second integral.

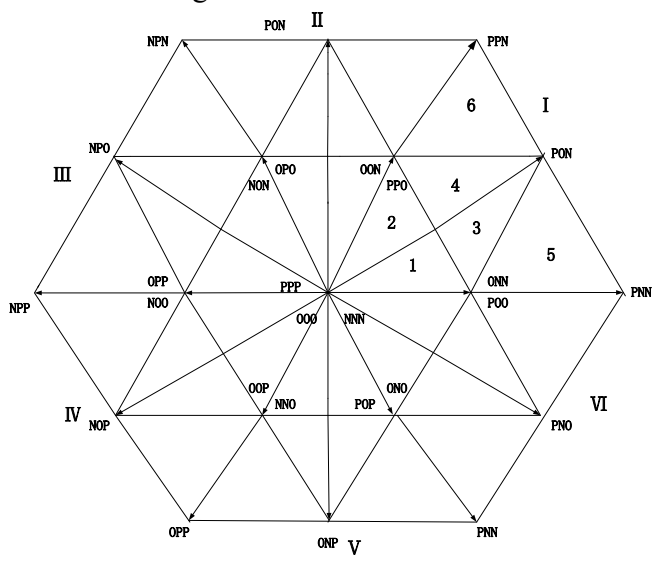

Figure 2. The space vector diagram of the SVPWM

Based on the vector magnitude, space voltage vectors can be divided into four types: large vectors, medium vectors, small vectors and zero vectors. The division of voltage vectors is shown in Table 1 . The lager vectors are located at the vertices of the outer hexagon and have the magnitude of $2 / 3 \mathrm{U}_{\mathrm{dc}}$; the medium vectors are located at the middle of the outer hexagon and the magnitude of $\sqrt{3} / 3 \mathrm{Udc}$. The small vectors are located at the vertices of the inner hexagon and have the magnitude of $1 / 3 U_{\mathrm{dc}}$; and the zero vectors have the magnitude of zero. Each small vector has two switching states, one is corresponding to "P" state, which is called positive small vector, and the other is corresponding to " $\mathrm{N}$ " state, which is called negative small vector.

The four types of vectors have different effects on neutral point voltage deviation, it is summarized that the zero and large vectors do not affect the neutral point voltage; the medium vectors affect the neutral point voltage, but one medium vector is only corresponding to one switching state, and thus we would not realize neutral point voltage control through medium vectors. But the small vectors have specific effect on the neutral point voltage, because one small vector is corresponding to two inverse switching states. The positive small vector will lead to rise of the neutral point voltage; and the negative small vector operation will lead to drop of the neutral point voltage. The power flow depends on the direction of the DC-link current. In contrary, if the current direction is different, the small vectors will have opposite effect on the neutral point voltage.

Table 1. The divides of vector types

\begin{tabular}{lc}
\hline Vector type & Switching state \\
\hline Large vector & PNN, PPN, NPN, \\
Medium vector & PON, NNP, PNP \\
& NOP, OPN, PNO \\
Small vector & POO-ONN, PPO-OON \\
& OPO-NON, OPP-NOO \\
& OOP-NNO, POP-ONO \\
Zero vector & PPP, OOO, NNN \\
\hline
\end{tabular}

3 NEUTRAL POINT BALANCE CONTROL STRATEGY BASED ONREGULATING FACTOR

\subsection{The effects of four types of voltage vectors}

In this paper, a SVPWM strategy is proposed to maintain the neutral point voltage balance. The switching sequence of this strategy is the same as that of conventional NTV SVPWM algorithm. Figure 3 shows different effects of four types of voltage.

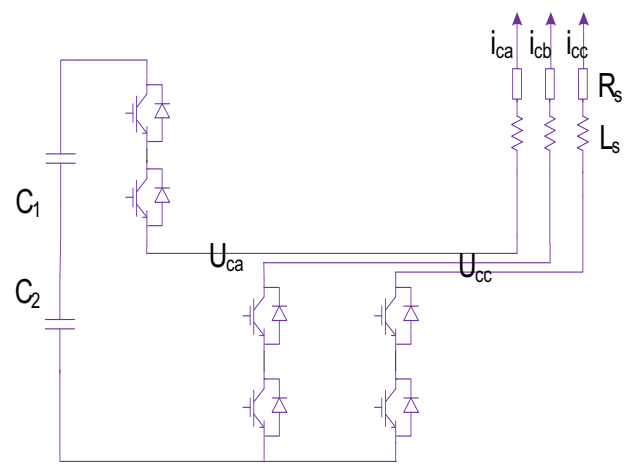

Figure 3. (a) Large vector "PNN" 


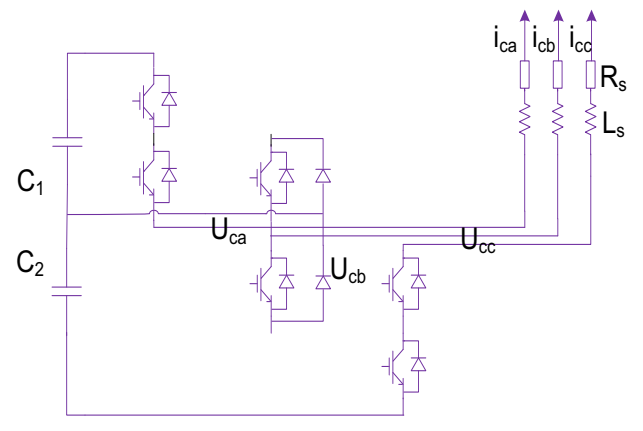

Figure 3. (b) Medium vector "PON"

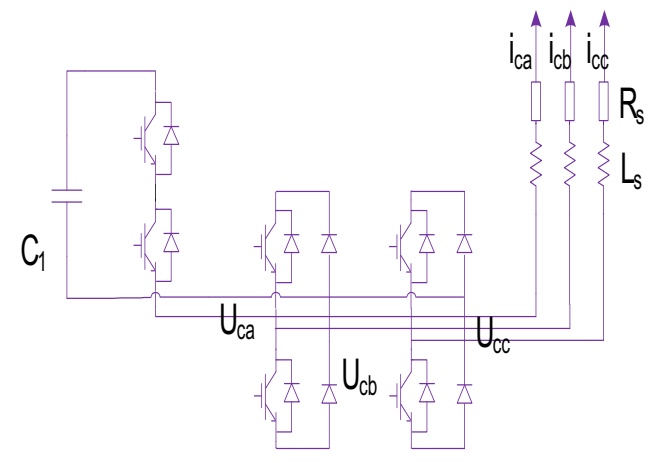

Figure 3. (c) Positive small vector "POO"

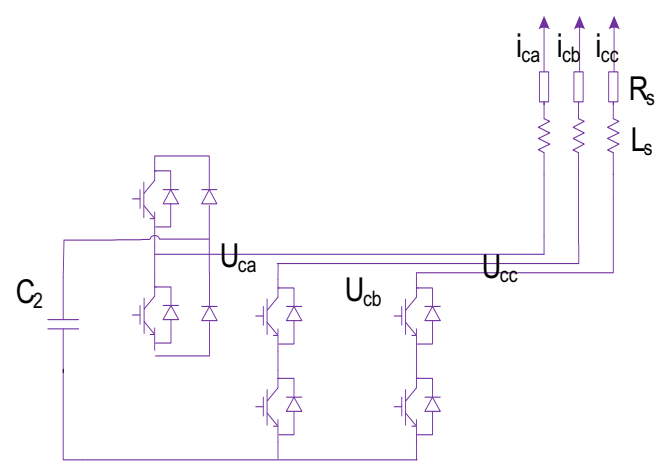

Figure 3. (d) Negative small vector "ONN"

Then, we will analyze the effects of four types of voltage vectors on neutral point voltage combined with examples.

The state "PNN" is chosen as the example of large vectors, and the corresponding circuit topology is shown in Figure 3(a). From the figure we can see that the $\mathrm{AC}$ output phase $\mathrm{A}$ is connected with the top of the DC-link capacitor $\mathrm{C} 1$, and phase $\mathrm{B}$ and $\mathrm{C}$ are connected with the bottom of the DC-link capacitor $\mathrm{C} 2$ in parallel. The current value of capacitor $\mathrm{C} 1$ and $\mathrm{C} 2$ is equal to $i_{\text {ca. }}$. The two capacitors are charged and discharged simultaneously, therefore the voltage in creased and decreased on the two capacitors are keeping synchronous. Thus the large voltage vectors have no effects on the neutral point voltage.

The state "PON" is chosen as the example of medium vectors, the corresponding circuit topology is shown in Figure 3(b). From the figure we can see that the AC output phase A is connected with the top of the DC-link capacitor $\mathrm{C}_{1}$, and phase $\mathrm{B}$ is connected with the middle of DC-link capacitors and phase $\mathrm{C}$ is connected with the bottom of the DC-link capacitor $\mathrm{C}_{2}$ in parallel. The current value of capacitor $\mathrm{C}_{1}$ is $\mathrm{i}_{\mathrm{ca}}$, but the current of capacitor $C_{2}$ is equal to $i_{c c}$. Then the charged and discharged operation on two capacitors are not the same, therefore the voltage on the two capacitors will not keep synchronous. Thus the medium voltage vectors have direct effects on the neutral point voltage balance.

The state "PON" is chosen as the example of medium vectors, the corresponding circuit topology is shown in Figure 3(b). From the figure we can see that the $\mathrm{AC}$ output phase $\mathrm{A}$ is connected with the top of the DC-link capacitor $\mathrm{C} 1$, and phase $\mathrm{B}$ is connected with the middle of DC-link capacitors and phase $\mathrm{C}$ is connected with the bottom of the DC-link capacitor $\mathrm{C} 2$ in parallel. The current value of capacitor $\mathrm{C} 1$ is $\mathrm{i}_{\mathrm{ca}}$, but the current of capacitor $\mathrm{C} 2$ is equal to $\mathrm{i}_{\mathrm{cc}}$. Then the charged and discharged operation on two capacitors are not the same, therefore the voltage on the two capacitors will not keep synchronous. Thus the medium voltage vectors have direct effects on the neutral point voltage balance.

It can be seen in Table 1 that small vectors are always couples. In spite of that the output line voltages are the same under one couple of small vectors, however, the effects of the couple of the small vectors on the neutral point voltage are diametrically opposite. The states of "POO", "ONN" were chosen as examples of small vectors. The circuit topologies are shown in Figures 3(c) and (d). From the Figure 3(c), it can be seen that the output phase $\mathrm{A}$ is connected with the top of the DC-link capacitor $\mathrm{C} 1$, and phase $\mathrm{B}$ and $\mathrm{C}$ are connected with the bottom of the DC-link capacitor $\mathrm{C}_{1}$ in parallel. The current value of capacitor $C_{1}$ is equal to $i_{\text {ca }}$, but there is no current on capacitor $\mathrm{C}_{2}$. Thus the small voltage vectors have great effects on the neutral point voltage balance. We name state "POO" positive small vector. Oppositely, the corresponding circuit topology of state "ONN" is shown in Figure 3(d). It can be seen that the output phase $\mathrm{A}$ is connected with the top of the DC-link capacitor $\mathrm{C}_{2}$, phase $\mathrm{B}$ and $\mathrm{C}$ are connected with the bottom of the DC-link capacitor $\mathrm{C}_{2}$ in parallel. The current value of capacitor $\mathrm{C}_{2}$ is equal to $i_{\text {ca }}$, but there is no current on capacitor $C_{1}$. Thus the small voltage vectors which we name as negative have great effects on the neutral point voltage balance.

When zero vectors of "PPP", "OOO", and "NNN" operate, the output voltage of APF is zero; therefore there is no current on the DC-link capacitors. Thus 
zero vectors have no effects on the neutral point voltage balance. Table 2 shows the different effects of voltage vectors on the neutral point voltage balance.

Table 2. Different effects of voltage vectors on the neutral point voltage balance

\begin{tabular}{lll}
\hline Vector type & Voltage vector & $\begin{array}{l}\text { Effect on middle } \\
\text { voltage }\end{array}$ \\
\hline Zero vector & PPP, NNN, OOO & No effect \\
Large vector & PNN, PPN, NPN, & No effect \\
Medium vec- & PON, OPN, NPO & Have effect \\
tor & NOP, OPN, PNO & Have effect on \\
Positive small & POO, PPO, OPO & capacitor C1 \\
vector & OPP, OOP, POP \\
Negative small & ONN,OON,NON & $\begin{array}{l}\text { Have effect on } \\
\text { capacitor C2 }\end{array}$ \\
\hline
\end{tabular}

\subsection{Neutral point balance control strategy based on regulating factor}

This paper presents a novel neutral point balance control strategy which is based on regulating factor. The switching sequence of this strategy is the same as that of conventional NTV SVPWM algorithm. The negative small vector is chosen to be the first given vector, and thus for the proposed neutral point voltage balancing strategy, we just need to detect the actual direction of the current of the load which is connected with the middle of the DC-link capacitors when the small vectors operate. Then the effects of the small vectors will be clear, afterwards, through judging the offset direction of the voltage $\mathrm{U}_{\mathrm{c} 1}, \mathrm{U}_{\mathrm{c} 2}$ of the DC-link voltage, we can modulate the operation time of the small vectors, and then the balance of neutral point voltage will realize.

Now define $\Delta \mathrm{U}_{\mathrm{dc}}=\mathrm{U}_{\mathrm{c} 1}-\mathrm{U}_{\mathrm{c} 2}$.

When $\Delta U_{\mathrm{dc}}>0$, it means $\mathrm{U}_{\mathrm{c} 1}$ is bigger than $\mathrm{U}_{\mathrm{c} 2}$, so the positive small vector operation time should be increased to extend the discharge time of the capacitor $\mathrm{C}_{1}$ so that the voltage of $\mathrm{U}_{\mathrm{cl}}$ will decrease. Correspondingly, when $\Delta \mathrm{U}_{\mathrm{dc}}<0$, the negative small vector operation time should be increased to extend the charge time of the capacitor $\mathrm{C} 1$ so that the voltage on the capacitor $\mathrm{C} 1$ will increase. To avoid frequent switching of the power devices because of the tiny fluctuation, there should set a threshold $\mathrm{m}$. That is to say only when $\Delta \mathrm{U}_{\mathrm{dc}}>\mathrm{m}$ or $\Delta \mathrm{U}_{\mathrm{dc}}<-\mathrm{m}$, the balance strategy can operate. The Increased or decreased time of the small vectors operation can acquire through multiply primary operation time and a regulate factor $\mathrm{k}$. In consideration of the dead time of the PWM pulse switching, the value of $\mathrm{k}$ lies often between 0.25 and 0.75 . The specific control strategy is as follows:

When $-\mathrm{m}<=\Delta \mathrm{U}_{\mathrm{dc}}<=\mathrm{m}$, the value of $\mathrm{k}$ is 0.45 ;

When $\Delta \mathrm{U}_{\mathrm{dc}}>\mathrm{m}$, the current direction corresponding to the first given small vector is flowing to the system, the value of $\mathrm{k}<0.45$; oppositely, the value of $\mathrm{k}>0.45$.

Similarly, When $\Delta \mathrm{U}_{\mathrm{dc}}<-\mathrm{m}$, the current direction corresponding to the first given small vector is flow- ing to the APF, the value of $\mathrm{k}>0.45$; oppositely, the value of $k<0.45$.

Hereto, the regulation factor is obtained. The Table 3 shows the specific modulation strategy taking the large section 1 as example. Other sections are similar to the section 1 .

Table 3. Neutral point voltage control strategy in large section

\begin{tabular}{llll}
\hline $\begin{array}{l}\text { Middle } \\
\text { voltage }\end{array}$ & $\begin{array}{l}\text { First given } \\
\text { state }\end{array}$ & $\begin{array}{l}\text { Output } \\
\text { current }\end{array}$ & $\begin{array}{l}\text { Regulate factor } \\
\text { value }\end{array}$ \\
\hline & ONN & ia $>=0$ & $\mathrm{k}>0.45$ \\
& & $\mathrm{i}<<0$ & $\mathrm{k}<0.45$ \\
$\Delta \mathrm{Udc}>=0$ & OON & $\mathrm{ia}>=0$ & $\mathrm{k}<0.45$ \\
& & $\mathrm{i}<<0$ & $\mathrm{k}>0.45$ \\
& ONN & $\mathrm{ia}>=0$ & $\mathrm{k}<0.45$ \\
$\Delta \mathrm{Udc}<=0$ & OON & $\mathrm{ia}<0$ & $\mathrm{k}>0.45$ \\
& & $\mathrm{ia}>=0$ & $\mathrm{k}>0.45$ \\
& & $\mathrm{ia}<0$ & $\mathrm{k}<0.45$ \\
\hline
\end{tabular}

The Figure 5 shows the flow chart of the neutral point voltage control strategy. It can be seen that the three-phase reference voltages were transformed into two-phase voltages through Parker Transform and Clark Transform. Then the angle and the amplitude of the voltage vector can be separated from the two phase coordinate system. Combined with the amplitude of the DC-link voltage, the position in the vector diagram of the reference voltage can be judged by the angle and the amplitude. Next, the NTV SVPWM strategy was used to calculate the basic time of the voltage vectors, and then, combined with the neutral point voltage control strategy proposed by this paper, switching states were certainly determined.

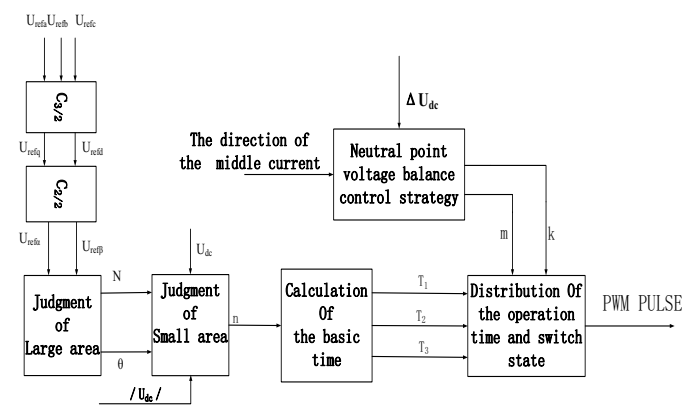

Figure 4. The neutral point voltage control strategy based on regulation factor

\section{SIMULATION RESULTS}

The validness of the control strategy is verified through simulations on the three-level NPC APF using Matlab Simulink package. DC-link voltage is set to $800 \mathrm{~V}$, and the initial voltage of the DC-link capacitors is set as: $\mathrm{U}_{\mathrm{C} 1}=410 \mathrm{~V}, \mathrm{U}_{\mathrm{C} 2}=390 \mathrm{~V}$ and the switching frequency is $1 \mathrm{KHz}$.

The voltage values shift of the two DC-link capacitors occurs when the system is working, and at $\mathrm{t}=0.06 \mathrm{~s}$ 
the control of the neutral point voltage is applied.

Figure 5 and Figure 6 show the voltage of the DC-link voltage on capacitor $\mathrm{C}_{1}, \mathrm{C}_{2}$. It can be seen that the voltage of $U_{c 1}$ and $U_{c 2}$ are changed to be steady after $\mathrm{t}=0.006 \mathrm{~s}$.

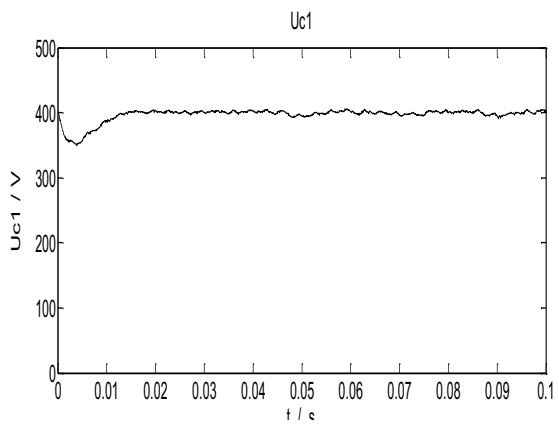

Figure 5. The voltage of capacitor $\mathrm{C}_{1}$

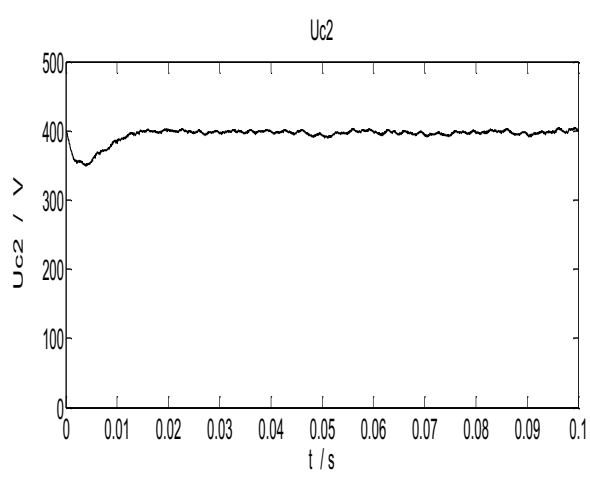

Figure 6. The voltage of capacitor $\mathrm{C}_{2}$

Clearly, it can be seen in Figure 7 that the voltage of DC-link is quickly becoming stable at $800 \mathrm{~V}$. In Figure 8 , it shows that the middle point voltage of the capacitor $\mathrm{C}_{1}$ and $\mathrm{C}_{2}$ is always close to zero.

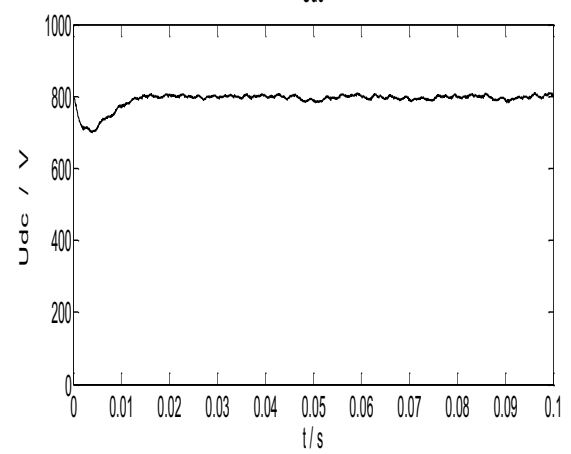

Figure 7. The voltage of DC-link

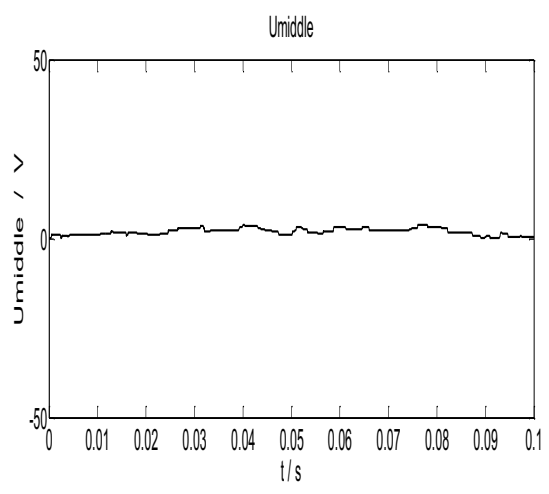

Figure 8 . The neutral point voltage

Figure 9 and Figure 10 show the AC phase voltage and line voltage, and they change little.

All the results illustrate that the neutral point voltage control strategy has excellent control precision.

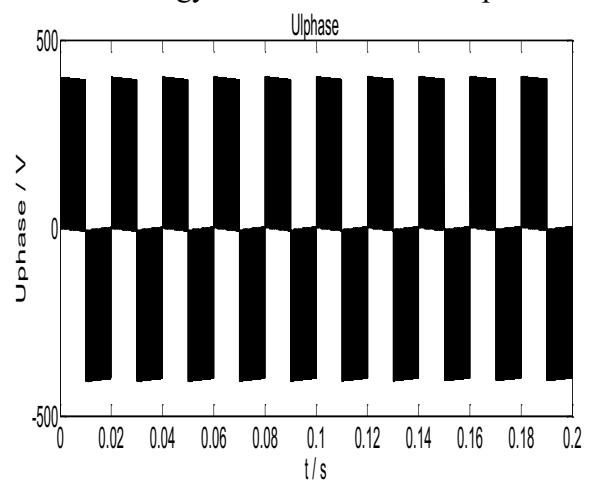

Figure 9. The voltage of AC output phase A

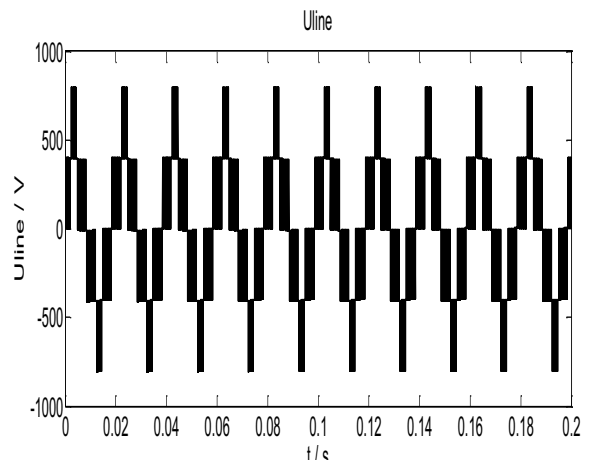

Figure 10. The line voltage of AC output

\section{CONCLUSION}

In this paper, a neutral point voltage balance control strategy based on regulation factor for three-level APF 
is presented. This strategy maintains the neutral point voltage balance by adjusting the small vector operation time. The causes of the neutral point unbalance are studied in detail, and the effects of different types of voltage vectors are analyzed. The operation time of the small voltage vectors were regulated by a variable factor which is followed with the current direction of the middle voltage of the DC-link capacitors. The new simple and effective method for neutral point voltage control is verified through simulation. Simulation results show that the proposed strategy presents good performance on neutral point voltage balance control.

\section{ACKNOWLEDGEMENTS}

This work is funded by a grant from the Shanghai municipal education commission research innovation fund under the project (13AZ03).

\section{REFERENCES}

[1] N. Celanovic, D. Boroyevich. 2000. A comprehensive study of neutral-point voltage balancing problem in three-level neutral-point-clamped voltage source PWM inverters. IEEE Trans. Power Electronics. 15(2): 242-249.

[2] T.Bruckner, S.Bernet, H.Guldner. 2005. The active NPC converter and its loss-balancing control. IEEE Trans. Industrial Electronics, 52(3): 855-868.

[3] J SaadMekhilef, Hudhaifa Ibrahim Khudhur \& Hamza Belkamel, 2012. DC Link Capacitor Voltage Balancing in Three Level Neutral point Clamped Inverter Control and Modeling for Power Electronics (COMPEL), 2012 IEEE 13th Workshop on, 42(1): 10-13.

[4] P.Chaturvedi, S.Jain, P. Agarwal, 2014. Carrier-based neutral point potential regulator with reduced switching losses for three-level diode-clamped inverter, Industrial Electronics, IEEE Transactions on, 61(2): 613-624.

[5] S.Busquets-Monge,S.Alepuz,J.Rocabert,J.Bordonau,200 9. Pulse width Modulations for the Comprehensive Capacitor Voltage Balance of n-Level Three-Leg Diode-Clamped Converters. IEEE Trans. Power Electronics, 24(5): 1364-1375.

[6] K.Yamanaka, A.M.Hava, H.Kirino, Y.Tanaka, N.Koga, T.Kume, 2002. A novel neutral point potential stabilization technique using the information of output current polarities and voltage vector. IEEE Trans. Industry Applications, 38(6): 1572-1580.

[7] L.M.Tolbert, T.G.Habetler, 1999. Novel multilevel inverter carrier-based PWM method. IEEE Trans. Industry Applications, 35(5): 1908-1107. 